\title{
Avaliação de Pastagem Diferida de Brachiaria decumbens Stapf. 2. Disponibilidade de Forragem e Desempenho Animal Durante a Seca ${ }^{1}$
}

\section{Eduardo Destéfani Guimarães Santos ${ }^{2}$, Mário Fonseca Paulino ${ }^{3}$, Domingos Sávio Queiroz ${ }^{4}$, Dilermando Miranda da Fonseca ${ }^{5}$, Sebastião de Campos Valadares Filho ${ }^{5}$, Rogério de Paula Lana ${ }^{5}$}

\begin{abstract}
RESUMO - Verificaram-se as disponibilidades de forragem total, forragem verde e morta e dos componentes folha verde, caule verde, folha seca e caule seco em pastagem diferida de Brachiaria decumbens. A pastagem foi vedada à entrada dos animais de dezembro de 1996 a junho de 1997 e avaliada, sob pastejo contínuo, durante a estação seca, nos meses de julho a outubro de 1997. Também foram estudadas correlações entre características do relvado e ganho de peso de tourinhos Limousin-Nelore com 19 meses e $374 \mathrm{~kg}$ de peso. O diferimento da pastagem de Brachiaria decumbens proporcionou disponibilidade média de forragem (DMST) de 7.568, forragem verde (DMSV) de 3.834 e morta (DMSM) de $3.734 \mathrm{~kg}$ de matéria seca (MS)/ha em julho, antes do período de pastejo. A utilização contínua da pastagem diferida durante o período seco, com lotação animal de 0,75 UA/ha, não afetou a DMST, média de 7.902, e DMSM, média de $4.637 \mathrm{~kg} / \mathrm{ha}$, mas afetou a DMSV e a disponibilidade de folhas verdes (DMSFV). A DMSV e a DMSFV apresentaram taxas crescentes em julho e outubro e diminuíram a taxas crescentes em agosto e setembro. No final de setembro, as pastagens apresentaram a menor DMSV, $2.540 \mathrm{~kg} / \mathrm{ha}$. A DMSFV e a proporção de folhas verdes no relvado foram maiores no início de agosto, respectivamente, $1.517 \mathrm{~kg} / \mathrm{ha}$ e $18,5 \%$, e menores no final de setembro, $480 \mathrm{~kg} / \mathrm{ha} \mathrm{e} 5,7 \%$, respectivamente. O diferimento da pastagem permitiu a manutenção dos animais e apenas pequeno ganho de peso durante a seca, média de $104 \mathrm{~g} /$ dia. Em setembro, os animais nas pastagens perderam peso. O ganho de peso vivo médio diário correlacionou-se linear e negativamente com DMSM e linear e positivamente com as relações [DMSV/DMSM] e [DMSFV/(DMSM + DMSCV)], em que DMSCV é a disponibilidade de matéria seca de caule verde. Não foram verificadas correlações entre ganho de peso e as variáveis DMSV, DMSFV, pressão de pastejo e oferta diária de forragem.
\end{abstract}

Palavras-chave: diferimento, pastagem tropical, produção animal em pastagem

\section{Evaluation of a Signalgrass (Brachiaria decumbens Stapf) Postponed Pasture. 2. Availability of Herbage and Animal Performance, During the Dry Season}

\begin{abstract}
The availability of herbage, green herbage, dead herbage, green leaf, green stem, dead leaf and dead stem components was evaluated in the Signalgrass (Brachiaria decumbens) pasture during the dry season, and after postponement period, from July to October 1997. The pasture characteristics were correlated with the average daily weight gain (ADG) of crossbred Limousin-Nelore males, aging 19 months and $374 \mathrm{~kg}$ body weight on average, from July to September 1997. The average availability of herbage was $7.568 \mathrm{~kg}$ dry matter (DM)/hectare (AH), green herbage (AGH) 3,834 kg DM/ha, and dead herbage (ADH) 3,734, in early July, after the postponement period of the Signalgrass pasture. The continuous utilization during the dry period of the postponed pasture, and stocking rate .75 animal units, did not affect $\mathrm{AH}$ and $\mathrm{ADH}$, respectively, 7,902 and 4,637 kg/ha on average; nevertheless, diminished the availability of green herbage and green leaf dry matter (AGL). The availability of green herbage and of green leaf component increased in July and October, and reduced at crescent rate from August to September. In late September, the average availability of green herbage reached least value, $2,540 \mathrm{~kg} \mathrm{DM} / \mathrm{ha}$. The availability and proportion of green leaf component in total herbage were greatest in early August, respectively, 1,517 kg DM/ha and 18.5\%, and were least in late September, respectively, $480 \mathrm{~kg} \mathrm{DM} / \mathrm{ha}$ and 5.7\%. The tropical pasture postponement warranted the maintenance of the animals, and leaded at a minimum average daily gain (ADG) (104 g/d), during the dry season. In September, the animals loosed body weight. ADG was linearly and negatively correlated with availability of dead dry matter, and it was linearly and positively correlated with the availability of green dry matter/dead dry matter ratio and green leaf dry matter/ dead dry matter plus green stem dry matter ratio. Had no correlation between the ADG and availability of green leaf, and between the ADG and availability of green herbage. ADG did not correlated with grazing pressure or with herbage availability.
\end{abstract}

Key Words: postponement, tropical pasture, animal production in a tropical pasture

\footnotetext{
${ }_{1}^{1}$ Parte da dissertação de Mestrado apresentada pelo primeiro autor junto ao Depto. de Zootecnia da Universidade Federal de Viçosa. 2 Engenheiro-Agrônomo, MS. E.mail: edestefani1@hotmail.com.br

3 Professor orientador DZO - UFV, bolsista do CNPq. E.mail: mpaulino@ufv.br

4 Zootecnista, DS, pesquisador EPAMIG.

5 Professor DZO - UFV, bolsista do CNPq
} 


\section{Introdução}

As variações sazonais nas características das pastagens exercem forte impacto na pecuária de corte brasileira, porque os animais são alimentados basicamente com pasto. Na estação seca, a produção forrageira é severamente reduzida, a senescência de folhas e perfilhos, acelerada, e as pastagens tropicais, especialmente aquelas mantidas sob pastejo, apresentam normalmente baixa disponibilidade de forragem de boa qualidade.

Nesse contexto, a incapacidade de sistemas de produção em ajustar suprimento com demanda de alimentos, quantitativa e qualitativamente, tem resultado, com muita freqüência, na subnutrição dos animais durante esse período crítico, com conseqüente redução da produtividade dos rebanhos de corte. Portanto, nos sistemas extensivos de produção, o controle do estoque e da qualidade de forragem, o controle da demanda e o ajuste oferta/demanda de alimentos são aspectos importantes e não devem ser negligenciados (Faria et al., 1997).

Nos Cerrados, o diferimento de pastagens é uma das poucas providências adotadas pelos pecuaristas para aumentar a disponibilidade de forragem durante a estação seca e fria. Essa prática tem contribuído para a persistência de pastagens, sobrevivência de animais e aumento da taxa de lotação nesse período. No entanto, o simples diferimento de pastagens pode não produzir os resultados que determinados sistemas de produção necessitam para atingir suas metas de produtividade. Segundo Gomide (1997), em pastagens na fase de crescimento, após o perfilhamento inicial, instalam-se os processos fisiológicos de alongamento do colmo, intensificação da senescência de folhas e diminuição da área foliar. Se o pasto não for utilizado, o contínuo aumento do rendimento forrageiro, em virtude principalmente do alongamento das hastes, resulta em crescente aumento da proporção de colmos e diminuição da relação folha/colmo na biomassa da pastagem. Conforme Blaser (1994), Leite \& Euclides (1994) e Noller et al. (1997), pastagens com baixa disponibilidade de folhas verdes e alta de caule e material morto são, normalmente, pouco consumidas, podendo implicar em baixa produtividade dos animais nessas condições.

De forma geral, as pastagens apresentam distintos potencial de consumo de matéria seca (CMS) e valor nutritivo, características que são continuamente modificadas de acordo com alterações nos compo- nentes do ecossistema e interações entre eles. $\mathrm{Na}$ estimação desses parâmetros, deve-se considerar também que, quando a produção das pastagens é medida em termos de produção animal, as características dos animais usados têm importante relação com os resultados finais obtidos (Ivins et al., 1958).

De acordo com Allden \& Whittaker (1970), os principais fatores que condicionam o comportamento ingestivo de animais em pastagens, caracterizado pelo tamanho e taxa de bocado e tempo de pastejo, podem ser divididos em dois grupos: um relacionado ao animal e outro atribuído às características do relvado. As características associadas aos animais dizem respeito à espécie, à idade, ao biótipo, sexo, peso corporal, estádio fisiológico e às características alométricas relativas à apreensibilidade de uma forragem, como tamanho da boca, entre outras. As principais características da pastagem que influenciam o consumo de pasto são disponibilidade e qualidade de forragem e estrutura do relvado, que dependem da espécie forrageira, do manejo e edafoclima. As características estruturais da pastagem têm sido estudadas em termos de morfologia da planta; altura do relvado e densidade volumétrica de forragem, densidade de matéria seca verde e de folhas verdes em várias camadas da vegetação; proporção e disposição espacial dos tecidos vegetais preferidos; relação folha/caule; e presença de barreiras à desfolha, que pode ser avaliada pela proporção de caule e material morto na pastagem e por outros fatores que dificultam a seleção e colheita de forragem pelos animais.

De forma geral, quando a redução da disponibilidade dos componentes da forragem preferidos pelo animal começa a impor limitações à taxa na qual ele pode ingerir seu alimento (taxa de ingestão), percebe-se nítido aumento do tempo de pastejo. Verifica-se também que, embora o animal estenda o tempo de pastejo para compensar baixas taxas de ingestão de forragem, essa compensação pode tornar-se progressivamente mais incompleta e o consumo pode reduzir dramaticamente (Allden \& Whittaker, 1970). Isso ocorre porque as características do relvado influenciam grandemente a superfície coberta pelo pastejo e há um limite na distância que os animais percorrem e no número de horas que gastam diariamente nessa atividade (Mannetje \& Ebersohn, 1980). Em pastagens de espécies de Brachiaria e Panicum, Euclides et al. (1993) obtiveram correlações negativas entre tempo de pastejo e as variáveis: porcentagem de folhas verdes, disponibilidade de folhas ver- 
des, disponibilidade de matéria seca verde (DMSV) e ganho de peso (GPD) e correlação positiva entre tempo de pastejo e proporção de material morto na pastagem.

O tempo de pastejo é fator importante no CMS de animais em pastagens, especialmente para os bovinos, que têm pouca habilidade para selecionar alimento de melhor qualidade e, em conseqüência, necessitam ingerir maior quantidade de forragem para satisfazer seus requerimentos nutricionais. Por isso, o bovino é classificado como consumidor não seletivo de gramíneas e forragens (GF). Conforme Hofmann (1993), a capacidade de colher e utilizar determinados alimentos na pastagem são características dependentes do tipo morfofisiológico do animal. No entanto, conforme Guerrero et al. (1984), as quantidades de pasto que os animais deveriam ingerir para máximo ganho ou mesmo para mantença, quando se considera a qualidade da forragem disponível nas pastagens, são muito maiores que aquelas quantidades que os bovinos têm capacidade física de consumir. Este fato indica que o pastejo seletivo é necessário.

Freqüentemente, os animais em pastejo operam em seus limites físicos para colher e digerir forragem no afã de suprir seus requerimentos nutricionais. Todavia, em determinadas condições, o tempo máximo destinado ao pastejo pode ser insuficiente para que o animal consuma pasto até o ponto de atender seu requerimento energético ou mesmo de atingir a repleção ruminal. Nesse caso, os mecanismos de regulação que controlam o CMS de animais em pastejo diferem daqueles que normalmente controlam o consumo de animais confinados (Allden \& Whittaker, 1970).

Animais em relvados baixos ou esparsos têm dificuldade em atingir o consumo máximo e, quando o pasto está maduro e apresenta alta disponibilidade de matéria seca, também, há evidências de que eles têm dificuldade em colher alimento suficiente para satisfazer seus requerimentos nutricionais (Stobbs, 1973). Se a taxa de ingestão de matéria seca for criticamente baixa, o tempo de pastejo pode também ser limitado pela reduzida disponibilidade de energia para esse processo e o animal pode entrar em estado de inanição e morrer. Portanto, dentro do tempo que $\mathrm{o}$ animal pode destinar à atividade de pastejo e ruminação diariamente, o CMS pode ser limitado pela habilidade do animal em selecionar e colher os componentes mais digestíveis do relvado (Mannetje \& Ebersohn, 1980) e/ou pela sua capacidade de colher, mastigar e ruminar os componentes mais grosseiros (Welch, 1982), ingeridos em maiores proporções na dieta, à medida que os componentes preferidos se tornam escassos. Quando isto ocorre, o CMS e o desempenho animal podem cair rapidamente (Allden \& Whittaker, 1970; Stobbs, 1973).

Em pastagens subtropicais de melhor qualidade geral que as tropicais (Minson, 1990), há situações em que a disponibilidade de matéria seca total de forragem (DMST), avaliada indiretamente pela altura, é considerada o principal fator limitante do CMS e da produção animal; em outras, a qualidade da forragem. Minson (1990) afirmou que, quando a DMST está abaixo de $2.000 \mathrm{~kg}$ de MS/ha, o animal não atinge o consumo máximo; quando está acima, o CMS pode ser limitado por fatores relativos ao animal (controle físico ou fisiológico), dependendo da qualidade da forragem ingerida.

Já em pastagens tropicais, a DMST é considerada o principal fator limitante do consumo e da produção animal especialmente durante o início do crescimento vegetativo das gramíneas; mas, com o rápido desenvolvimento das forrageiras tropicais, há aumento extraordinário de colmos e de material morto na pastagem, dificultando o pastejo. As alterações químicas e estruturais do relvado, que acompanham o aumento da produção forrageira durante o desenvolvimento das gramíneas tropicais, fazem com que seja freqüentemente observada associação negativa entre produção ou disponibilidade de forragem e seu grau de utilização. Segundo Corsi et al. (1994), muitas vezes, esses fatores são responsáveis pela falta de correspondência entre DMST e produção animal.

Willoughby (1959), citado por Euclides et al. (1990), encontrou relação positiva entre DMSV e GPD dos animais em pastejo, porém não encontrou qualquer relação entre DMST e GPD. Mannetje \& Ebersohn (1980) afirmaram que, nos trópicos, o CMS e a produção animal se correlacionam com a DMSV; se essa disponibilidade for inferior a $2.000 \mathrm{~kg} / \mathrm{ha}$, podem ocorrer reduções do CMS e do desempenho animal. No entanto, fatores climáticos e elevada proporção de material morto na pastagem foram citados como as principais razões que não permitiram correlacionar CMS ou produção animal com DMSV em algumas situações. Conseqüentemente, a presença de forragem madura e de grande quantidade de material morto na pastagem podem limitar o uso de DMST e DMSV como instrumentos para predizer CMS e desempenho de animais em pastagens tropicais. 
Stobbs (1973), Mannetje \& Ebersohn (1980), Euclides et al. (1990), Cosgrove (1997) e Gomide (1997) mencionaram que a relação folha/colmo, a disponibilidade e densidade de folhas verdes, a presença de material morto e de inflorescências são fatores muito importantes que influenciam o consumo de pasto e o desempenho dos animais no ambiente tropical. Adicionalmente, Stobbs (1973) verificou que a baixa altura do relvado e baixa densidade volumétrica de folhas restringiram o consumo nos estádios mais precoces e mais tardios da planta forrageira, respectivamente.

Nesses casos, se o animal em pastejo não atinge o consumo máximo, a redução da pressão de pastejo pode ser ineficiente para aumentar o CMS ou a produção animal. De acordo com Allden \& Whittaker (1970), em situações nas quais os animais apresentam baixa taxa de ingestão de pasto, a redução da pressão de pastejo pode não compensar a baixa densidade de forragem de boa qualidade no esforço para aumentar o CMS e o desempenho desses animais. Por outro lado, o incremento da pressão de pastejo pode aumentar o grau de dificuldade de seleção de pasto e reduzir a acessibilidade ao pasto de melhor qualidade, afetando o CMS e/ou a qualidade do pasto ingerido. Conforme Hodgson et al. (1994), a preferência por um alimento ou um componente do pasto, normalmente de melhor qualidade, é demonstrada sob livre escolha e igual oportunidade de seleção, e a dieta selecionada é a colhida segundo a preferência, mas modificada pela acessibilidade, de acordo com a estrutura da vegetação e a oferta de forragem.

Do exposto, verifica-se a necessidade de caracterizar o potencial de produção animal de pastagens tropicais diferidas nas condições brasileiras e estudar os fatores que podem condicionar esse desempenho, apontando, por exemplo, as principais razões de os bovinos apresentarem, freqüentemente, baixos CMS e produção, a despeito das consideráveis disponibilidades de forragem nessas pastagens. Poucos dados estão disponíveis na literatura a respeito da oferta de forragem em pastagens diferidas e em situação real de pastejo, e também a respeito das alterações nas características dessas pastagens a partir do final do diferimento, sob a ação dos animais. Além disso, os conhecimentos disponíveis atualmente não mais indicam a existência de uma pressão de pastejo, ou oferta diária de forragem, ideal para todas as situações. Assim, a utilização mais eficiente das pastagens tropicais está na dependência de melhor entendimento da resposta da forrageira tropical ao manejo e da resposta dos animais ao ambiente de produção, especialmente na época da seca.

Nesse contexto, objetivou-se caracterizar pastagem diferida de Brachiaria decumbens em área de Cerrado, submetida a pastejo contínuo durante a estação seca, em termos de disponibilidade de forragem e disponibilidade dos componentes verdes e secos do pasto e, também, estudar fatores condicionantes do desempenho animal nesse ambiente de produção.

\section{Material e Métodos}

Esse trabalho foi conduzido na Fazenda Experimental de Felixlândia (MG), da EPAMIG, no período de dezembro de 1996 a outubro de 1997. Felixlândia situa-se a $18^{\circ} 04^{\prime} 04^{\prime \prime}$ de latitude Sul e $44^{\circ} 58^{\prime} 48^{\prime \prime}$ de longitude Oeste, no Alto-Médio São Francisco. A temperatura média anual é de $22,0^{\circ} \mathrm{C}$ e a precipitação, de $1200 \mathrm{~mm}$.

$\mathrm{O}$ experimento foi instalado em uma área com topografia plana, de solos profundos e bem drenados, cultivada com Brachiaria decumbens Stapf e subdividida em cinco piquetes de aproximadamente 8,9 ha cada. Os piquetes foram vedados em dezembro de 1996, após uma limpeza em novembro, como é feito tradicionalmente pelos produtores da região. Os pastos ficaram vedados até junho de 1997.

O ensaio com animais, com duração de 112 dias, foi dividido em quatro períodos experimentais de 28 dias e iniciou-se em 8 de junho de 1997. Nas datas: 8 de julho, 7 de agosto, 9 e 30 de setembro e 29 de outubro, foram efetuadas amostragens dos pastos com auxílio de quadrado de ferro com área de $1 \mathrm{~m}^{2}$, para obtenção de 10 amostras simples por piquete e por data de amostragem. O corte foi feito rente ao solo, de acordo com McMeniman (1997), colhendose toda a forragem na área do quadrado. As amostras foram pesadas individualmente e dessas retiraram-se amostras compostas por piquete e data. As amostras compostas de forragem assim obtidas foram utilizadas para a separação dos componentes da gramínea: folha verde (FV), caule verde (CV), folha seca (FS) e caule seco (CS). Bainhas foliares firmemente aderidas ao caule e inflorescências foram incluídas como caule. Os componentes verdes constituíram a matéria seca verde (MSV) e os componentes secos ou mortos, a matéria seca morta (MSM).

As disponibilidades de matéria seca de forragem total (DMST), matéria seca verde (DMSV), matéria seca de folha verde (DMSFV), matéria seca de caule 
verde (DMSCV), matéria seca de folha seca (DMSFS), matéria seca de caule seco (DMSCS) e matéria seca morta (DMSM), por piquete e data, foram calculadas multiplicando-se as estimativas de disponibilidade em matéria natural pelos respectivos teores de matéria seca (MS). As disponibilidades dos componentes da forragem, por data, foram avaliadas por meio de análise de variância e as médias, comparadas pelo teste Tukey e nível de significância de 5\%. As taxas de incremento ou redução da disponibilidade das frações do relvado foram estimadas dividindo-se a diferença de suas disponibilidades entre duas datas pela disponibilidade das respectivas frações no início do período considerado e pelo número de dias entre as avaliações, vezes 100 .

Cada piquete de capim-braquiária foi utilizado por oito tourinhos $F_{1}$ Limousin $x$ Nelore, em ensaio com suplementos descrito por Santos (2000). Os ganhos de peso (GPD) dos animais não suplementados, com média de 19 meses de idade e $374 \mathrm{~kg}$ de peso, foram avaliados por meio de análise de variância e as médias, por período, comparadas usando-se o teste de Tukey e nível de significância de $5 \%$ de probabilidade. Ajustaram-se equações de regressão para GPD, em função das seguintes características da pastagem: DMST, DMSV, DMSM, DMSFV, DMSFS, DMSCV e DMSCS, ou relações envolvendo esses parâmetros. As informações do mês de outubro não foram incluídas nesses cálculos. Também foram utilizados dados sobre a qualidade da forragem colhida pelos animais (extrusa), de CMS e da concentração de nutrientes digestíveis totais (NDT) no pasto, obtidas com o auxílio de tourinhos $\mathrm{F}_{1}$ Limousin $\mathrm{x}$ Nelore, fistulados no esôfago e rúmen, no peródo de 18 a 22/08, 01 a $05 / 09$ e 27 a 31/10 (Santos, 2000). Não foi possível a obtenção dessas informações no mês de julho.

A pressão de pastejo (PP) foi calculada como o peso vivo animal (PV) por área de pastagem, dividido pela DMSV estimada no início do período, por período (número de dias) de ocupação do piquete (PO). A oferta diária de forragem (ODF) foi estimada como a DMSV, dividida pelo período de ocupação do piquete $(\mathrm{PO})$, por $100 \mathrm{~kg}$ PV/área. Assim: $\mathrm{PP}=(\mathrm{PV} /$ área)/(DMSV/PO), em $\mathrm{kg}$ de $\mathrm{PV} / \mathrm{kg}$ de MSV/dia; e $\mathrm{ODF}=100 *(\mathrm{DMSV} / \mathrm{PO}) /(\mathrm{PV} /$ área $), \mathrm{em} \mathrm{kg}$ de $\mathrm{MSV} / \mathrm{dia} / 100 \mathrm{~kg}$ de PV ou simplesmente \%. A PP pode ser convertida para ODF, e vice-versa, usando-se a expressão: PP $*$ ODF $=100$. A taxa média de lotação foi de 0,75 unidade-animal (UA)/ha.

\section{Resultados e Discussão}

Constam na Tabela 1 os dados climáticos verificados durante os períodos pré-experimental (dezembro/1996 a junho/1997) e experimental (julho a outubro/1997). Em virtude da ocorrência de chuvas, acima da média histórica de $1.200 \mathrm{~mm}$, e do longo período de diferimento das pastagens, verificaram-se altos valores médios de DMST $(7.902 \mathrm{~kg} / \mathrm{ha})$ e de DMSM ( $4.637 \mathrm{~kg} / \mathrm{ha})$ no decorrer do período seco. A DMSV média foi de $3.265 \mathrm{~kg} / \mathrm{ha}$. Gomes Jr. (2000) observou DMST média de $6.454 \mathrm{~kg} / \mathrm{ha}$ em pastagem de Brachiaria decumbens entre os meses de agosto e outubro, em condições semelhantes às deste trabalho. Em algumas áreas, constatou-se acamamento do capim, ocorrido em função da altura atingida pelas plantas forrageiras, e que foi acentuado pela ação dos animais durante o período de pastejo.

Na Figura 1, são apresentadas as DMST e DMSV por data de amostragem. As disponibilidades de forragem total e verde estiveram sempre acima dos valores considerados críticos por Minson (1990) e Mannetje \& Ebersohn (1980), de 2.000 kg/ha, respectivamente, como limites mínimos de DMST e DMSV, abaixo das quais poderia ocorrer redução do CMS pelos animais em pastejo. Esses autores reconheceram que outros fatores também podem influenciar o CMS, independentemente desses limites serem alcançados ou não.

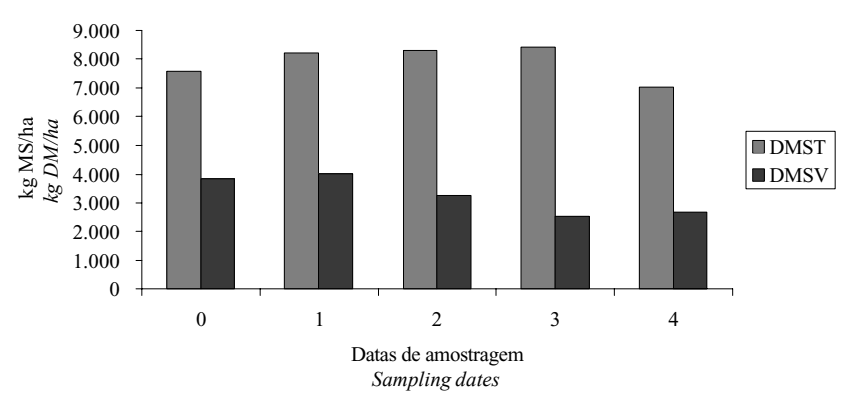

Figura 1 - Disponibilidade de matéria seca total (DMST) e matéria seca verde (DMSV) de Brachiaria decumbens sob pastejo contínuo, por data de amostragem (início, $0=8 /$ jul; 1 = 7/ago; $2=9 /$ set; $3=30 /$ set e $4=29$ /out) .

Figure 1 - Total dry matter (DMST) and green dry matter (DMSV) forage availability in the Brachiaria decumbens pasture under continuous grazing, according to the sampling dates (beginning, $0=\mathrm{Jul} / 8 ; 1$ = Aug/7; 2 = Sep/9; 3 = Sep/30 e 4 = Oct/29). 
Tabela 1 - Médias mensais de umidade relativa (UR), temperatura média do ar e precipitação pluviométrica

Table 1 - Averages monthly of relative humidity $(\mathrm{RH})$, air temperature, and rainfall

\begin{tabular}{|c|c|c|c|c|}
\hline $\begin{array}{l}\text { Ano } \\
\text { Year }\end{array}$ & $\begin{array}{c}\text { Mês } \\
\text { Month }\end{array}$ & $\begin{array}{l}\mathrm{UR}(\%) \\
R H(\%)\end{array}$ & $\begin{array}{l}\text { Temperatura média }\left({ }^{\circ} \mathrm{C}\right) \\
\text { Average temperature }\left({ }^{\circ} \mathrm{C}\right)\end{array}$ & $\begin{array}{l}\text { Precipitação }(\mathrm{mm}) \\
\text { Rainfall }(\mathrm{mm})\end{array}$ \\
\hline 1996 & $\begin{array}{l}\mathrm{dez} \\
\text { Dec }\end{array}$ & 78,5 & 24,5 & 288,8 \\
\hline \multirow{17}{*}{1997} & Jan & 81,4 & 24,9 & 327,0 \\
\hline & $\begin{array}{l}\text { Jan } \\
\text { Feev }\end{array}$ & 64,4 & 24,6 & 30,2 \\
\hline & $F e b$ & & & \\
\hline & Mar & 72,1 & 23,6 & 243,4 \\
\hline & Mar & 717 & 227 & 269 \\
\hline & $A p r$ & & & \\
\hline & Mai & 71,7 & 19,7 & 30,6 \\
\hline & May & & & \\
\hline & Jun & 69,9 & 18,4 & 44,2 \\
\hline & Jun & & & \\
\hline & Jul & 59,7 & 19,0 & 0,0 \\
\hline & Jul & & & \\
\hline & Ago & 54,0 & 19,8 & 0,0 \\
\hline & Aug & & & \\
\hline & $\begin{array}{l}\text { Set } \\
\text { Sep }\end{array}$ & 55,2 & 25,1 & 29,0 \\
\hline & Out & 63,5 & 26,3 & 78,0 \\
\hline & $O c t$ & & & \\
\hline
\end{tabular}

Na Tabela 2, são apresentadas as disponibilidades de forragem total e verde e de matéria seca dos componentes FV, CV, FS e CS na pastagem. Embora a DMST não tenha sido influenciada pela data de amostragem ( $\mathrm{P}>0,05)$, o incremento de $11,2 \%$, de $7.568 \mathrm{~kg} / \mathrm{ha}$ em julho para $8.418 \mathrm{~kg} / \mathrm{ha}$ no final de setembro, e redução substancial $(\mathrm{P}<0,05)$ da DMSV em $36,8 \%$, de $4.021 \mathrm{~kg} /$ ha no início de agosto para $2.540 \mathrm{~kg} / \mathrm{ha}$ no final de setembro, fizeram com que, nessa época, as pastagens se apresentassem com maiores valores de DMST e DMSM e menor $(\mathrm{P}<0,05)$ DMSV.

Foram observados aumentos $(\mathrm{P}<0,05)$ dos valores de DMSFV $(39,7 \%)$ e DMSFS $(69,0 \%)$ e reduções dos valores de DMSCV $(-8,9 \%)$ e DMSCS $(-24,8 \%)$ de julho para agosto. Segundo Paulino (1999), incrementos na DMSFV, nessas condições, são devidos ao impacto dos animais sobre a vegetação fisiologicamente madura, provocando redução dos tecidos senescentes que inibem a rebrotação dos pastos.

A DMSFV aumentou a taxas de, respectivamente,
Tabela 2 - Médias de disponibilidade ( $\mathrm{kg} / \mathrm{ha})$ de matéria seca total (DMST), matéria seca verde (DMSV), matéria seca de folha verde (DMSFV), matéria seca de caule verde (DMSCV), matéria seca de folha seca (DMSFS) e matéria seca de caule seco (DMSCS) de Brachiaria decumbens, nas datas de amostragem

Table 2 - Means of availability ( $\mathrm{kg} \mathrm{DM} / \mathrm{ha}$ ) of forage dry matter (DMST), green dry matter (DMSV), green leaf dry matter (DMSFV), green stem dry matter (DMSCV), dead leaf dry matter (DMSFS), and dead stem dry matter (DMSCS) in the Brachiaria decumbens pasture, in sampling dates

\begin{tabular}{|c|c|c|c|c|c|}
\hline \multirow[t]{2}{*}{$\begin{array}{l}\text { Parâmetros } \\
\text { Parameters }\end{array}$} & \multicolumn{5}{|c|}{$\begin{array}{l}\text { Época de amostragem } \\
\text { Sampling dates }\end{array}$} \\
\hline & $\begin{array}{l}\text { 8/jul } \\
\text { Jul/8 }\end{array}$ & $\begin{array}{l}\text { 7/ago } \\
\text { Aug/7 }\end{array}$ & $\begin{array}{l}\text { 9/set } \\
\text { Sep/9 }\end{array}$ & $\begin{array}{l}\text { 30/set } \\
\text { Sep/30 }\end{array}$ & $\begin{array}{l}\text { 29/out } \\
\text { Oct/29 }\end{array}$ \\
\hline DMST & $7568^{a}$ & $8191^{a}$ & $8311^{\mathrm{a}}$ & $8418^{a}$ & $7021^{a}$ \\
\hline DMSV & $3834^{\mathrm{ab}}$ & $4021^{\mathrm{a}}$ & $3250^{\mathrm{ab}}$ & $2540^{\mathrm{b}}$ & $2681^{a b}$ \\
\hline DMSFV & $1086^{\mathrm{b}}$ & $1517^{\mathrm{a}}$ & $881^{\mathrm{b}}$ & $480^{c}$ & $699^{b c}$ \\
\hline DMSCV & $2748^{a}$ & $2504^{a}$ & $2369^{a}$ & $2060^{a}$ & $1982^{a}$ \\
\hline DMSFS & $1451^{\mathrm{b}}$ & $2453^{\mathrm{ab}}$ & $2344^{\mathrm{ab}}$ & $2954^{\mathrm{a}}$ & $1912^{\mathrm{ab}}$ \\
\hline DMSCS & $2282^{\mathrm{a}}$ & $1717^{\mathrm{a}}$ & $2718^{\mathrm{a}}$ & $2924^{\mathrm{a}}$ & $2427^{a}$ \\
\hline
\end{tabular}

Médias seguidas por letras diferentes na mesma linha diferem $(P<0,05)$ pelo teste Tukey.

Means in the line with different letters differ $(P<.05)$ by Tukey test. 
1,32 e 1,57\%/dia, em julho e outubro com o início das chuvas, e reduziu a taxas médias crescentes de $-1,27$ e $-2,17 \% /$ dia, em agosto e setembro. A redução $(\mathrm{P}<0,05)$ na DMSFV do início de agosto para o final de setembro foi de $68 \%$ (de 1.517 para $480 \mathrm{~kg} / \mathrm{ha}$ ) e refletiu, provavelmente, o pastejo seletivo, a redução da taxa de produção forrageira e o aumento da taxa de senescência das folhas, no período mencionado. Com o início do período chuvoso em outubro, verificaram-se aumento no valor de DMSFV $(45,6 \%)$ e redução no de DMST $(-16,6 \%)$.

O componente FV constituía inicialmente o principal componente da camada superior do relvado e, aos poucos, em razão do pastejo seletivo, dispôs-se, gradativamente, no interior da massa forrageira, em pequenos e novos perfilhos que surgiram do desenvolvimento de gemas laterais. Stobbs (1973) relatou que o maior consumo de folhas do extrato do relvado mais acessível ao animal resulta em maior proporção de caules e inflorescências e menor densidade de folhas verdes nessa camada. Conforme Hodgson et al. (1994), em virtude do pastejo seletivo, ocorrem, na maioria das circunstâncias de pastejo, diminuição da fração FV e conseqüente redução do valor nutritivo da forragem remanescente, uma vez que essa fração da forragem contém maiores concentrações de energia digestível, proteína bruta e minerais.

Apesar de a DMSCV não ter sido influenciada $(\mathrm{P}>0,05)$ pela data de amostragem, o seu valor médio foi reduzido a taxas variáveis, durante todo o experimento, sendo maior em setembro, de $-0,62 \% / \mathrm{dia}$, e menor no início das chuvas, em outubro, $-0,13 \% /$ dia. Do início ao final do ensaio no campo, o valor da DMSCV diminuiu 27,9\%. Já a DMSV variou de forma intermediária à de seus componentes $\mathrm{FV}$ e $\mathrm{CV}$, foi maior $(\mathrm{P}<0,05)$ no início de agosto e menor $(\mathrm{P}<0,05)$ no final de setembro.

A DMSFS foi incrementada $(\mathrm{P}<0,05)$ em $20,4 \%$ do início de julho ao final de setembro. Do final de setembro para o final de outubro, verificou-se grande diminuição dos tecidos senescentes com o início das chuvas. A redução do valor da DMSFS em 35,3\%, nesse período, pode ter sido conseqüência de maior taxa de incorporação dessa fração à liteira do solo, além de indicativo de que esse componente foi produzido a menores taxas, uma vez que o estoque de FV era muito baixo na data de amostragem anterior e/ou que foi mais consumido pelos animais nesse período, embora a presença de FV já apresentasse taxas crescentes. $\mathrm{O}$ valor da DMSCS aumentou em
$70,3 \%$ do início de agosto ao final de setembro e reduziu em $17 \%$ do final de setembro ao final de outubro, embora não tenha sido influenciado pela data de amostragem.

O período entre julho e início de agosto foi caracterizado como aquele em que as pastagens apresentaram maior $(\mathrm{P}<0,05)$ DMSV e DMSFV e menor $(\mathrm{P}<0,05)$ DMSFS; e o final de setembro, como a época mais crítica da seca, com menores $(\mathrm{P}<0,05)$ DMSV e DMSFV e maior $(\mathrm{P}<0,05)$ DMSFS. Apenas no início da seca, a pastagem mostrou-se com razoável disponibilidade de $\mathrm{FV}$.

As proporções de FV, CV, FS e CS na forragem disponível estão mostradas na Figura 2, segundo a data de amostragem. A porcentagem de FV na forragem disponível foi muito baixa durante todo o experimento e maior $(\mathrm{P}<0,05)$ no início de agosto $(18,5 \%)$, atingindo nível crítico $(\mathrm{P}<0,05)$ no final de setembro, média de $5,7 \%$ da DMST. O valor da proporção de $\mathrm{CV}$ na forragem disponível reduziu continuamente de julho $(36,3 \%)$ até o final de setembro $(24,5 \%)$. Com o início das chuvas no mês de outubro, o valor da proporção de FV na pastagem aumentou e, embora o valor da disponibilidade de CV tenha diminuído, o valor de sua proporção também aumentou, em virtude de maior redução na DMST. A menor $(\mathrm{P}<0,05)$ proporção de FS no pasto ocorreu no início do experimento, em julho (19,2\%), e a maior $(\mathrm{P}<0,05)$, no final de setembro ( $35,1 \%$ da DMST). A

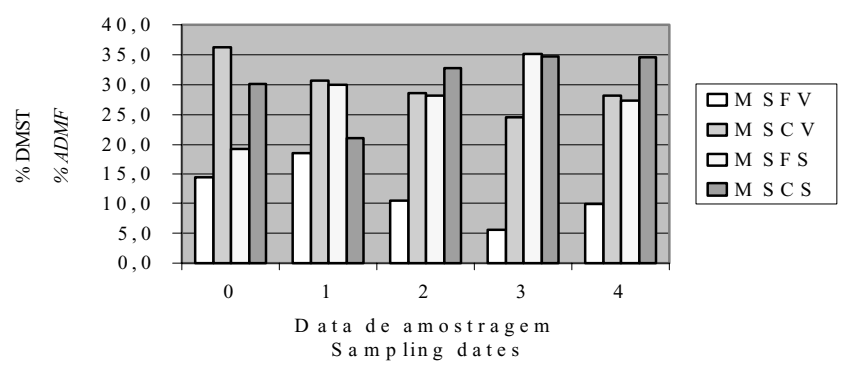

Figura 2 - Médias das proporções de matéria seca de folha verde (MSFV), caule verde (MSCV), folha seca (MSFS) e caule seco (MSCS), expressas como porcentagens da disponibilidade total de matéria seca (DTMS), em pastagem de Brachiaria decumbens, por data de amostragem.

Figure 2 - Means of proportions of green leaf (MSFV), green stem (MSCV), dry leaf (MSFS) and dry stem dry matter (MSCS) in the Brachiaria decumbens pasture, in different periods, expressed like availability of dry matter forage (ADMF) percentage. 
Tabela 3 - Teores médios ( $\mathrm{g} / 100 \mathrm{~g}$ de MS) de proteína bruta (PB), fibra em detergente neutro (FDN), fibra em detergente ácido (FDA) e lignina (LIG), em amostras de Brachiaria decumbens (extrusa), consumos médios diários de matéria seca (CMS) de pasto, expressos em porcentagem do peso vivo ( $\% \mathrm{PV}$ ) e em matéria seca (MS) por unidade de tamanho metabólico (g de $\mathrm{MS} /\left(\mathrm{kg} \mathrm{PV}^{0,75}\right)$ ), e teor de nutrientes digestíveis totais aparente (NDT), por período

Table 3 - Average contents $(g / 100 \mathrm{~g} \mathrm{DM})$ of crude protein $(C P)$, neutral detergent fiber (NDF), acid detergent fiber (ADF) and lignin (LIG), in samples of Brachiaria decumbens pasture (extrusa), and means of forage dry matter intake (DMI), expressed as live weight percentage (\% LW) and metabolic weight ( $g$ of $\left.D M /(\mathrm{kg} L W)^{0.75}\right)$, and average contents of total digestible nutrients (TDN), according to the period

\begin{tabular}{|c|c|c|c|}
\hline \multirow[t]{2}{*}{$\begin{array}{l}\text { Item } \\
\text { Item }\end{array}$} & \multicolumn{3}{|c|}{$\begin{array}{l}\text { Períodos } \\
\text { Periods }\end{array}$} \\
\hline & $18-22 / 08$ & $1-5 / 09$ & $27-31 / 10$ \\
\hline $\begin{array}{l}\text { PB } \\
C P\end{array}$ & $5,92^{\mathrm{ab}}$ & $4,46^{\mathrm{b}}$ & $8,47^{\mathrm{a}}$ \\
\hline $\begin{array}{l}\text { FDN } \\
N D F\end{array}$ & 73,87 & 74,73 & 72,31 \\
\hline $\begin{array}{l}\text { FDA } \\
A D F\end{array}$ & 38,27 & 41,14 & 38,53 \\
\hline LIG & 9,40 & 9,12 & 8,99 \\
\hline CMS (\% PV) & $1,46^{\mathrm{a}}$ & $1,40^{\mathrm{a}}$ & $0,82^{\mathrm{b}}$ \\
\hline $\begin{array}{c}D M I(\% L W) \\
\left.\mathrm{CMS}\left(\mathrm{g} \mathrm{MS}^{2}\left(\mathrm{~kg} \mathrm{PV}^{0,75}\right)\right)\right) \\
D M I\left(g \mathrm{~g} M /\left(\mathrm{kg} L W^{0.75}\right)\right)\end{array}$ & $58,67^{\mathrm{a}}$ & $56,18^{a}$ & $33,56^{\mathrm{b}}$ \\
\hline $\begin{array}{l}\text { Teor NDT }(\%) \\
T D N \text { content }(\%)\end{array}$ & $31,49^{a}$ & $30,50^{\mathrm{a}}$ & $23,70^{\mathrm{b}}$ \\
\hline
\end{tabular}

Médias seguidas por letras diferentes na mesma linha diferem $(P<0,05)$ pelo teste Tukey.

Means in the same row with different letters differ $(P<.05)$ by Tukey test.

proporção média de CS no pasto foi menor $(\mathrm{P}<0,05)$ no início de agosto $(21,0 \%)$ e logo atingiu valor acima de $30 \%$ da DMST, que persistiu mesmo após o início das chuvas.

A proporção de MSV diminuiu $(\mathrm{P}<0,05)$ de $50,7 \%$, no início de julho, para $30,2 \%$, no final de setembro, enquanto a de matéria seca morta aumentou $(\mathrm{P}<0,05)$ de 49,3 para $69,8 \%$ da DMST. Somente no final de outubro, verificou-se aumento da proporção de MSV no pasto, em decorrência do início do período chuvoso. Durante todo o período de utilização da pastagem, a porcentagem de material morto foi extremamente elevada.

Embora a disponibilidade de forragem fosse muito alta, estimativas de CMS realizadas com utilização de animais fistulados (Tabela 3) indicaram que cada animal consumiu em torno de $160 \mathrm{~kg}$ de MS de pasto (5,7 kg de MS/dia) por 28 dias (média entre as épocas 18 a 22/08 e 1 a 5/09), valor equivalente ao consumo diário de $1,4 \%$ do PV ou $57,4 \mathrm{~g} \mathrm{MS} / \mathrm{kg}^{0,75}$. Assim, a forragem consumida nesse período correspondeu a somente $1,9 \%$ da DMST (média de $8.251 \mathrm{~kg} / \mathrm{ha}$ ) ou de $4,4 \%$ da DMSV (3.636 kg/ha no período considerado). $\mathrm{Na}$ ocasião, o pasto apresentou $31,5 \%$ de NDT e digestibilidade aparente de 35,4\% (Santos, 2000); no entanto, o CMS de pasto verificado em 27 a 31/10 foi mais baixo ainda, provavelmente, devido à drástica redução da disponibilidade e proporção de $\mathrm{FV}$ e ao aumento de material morto na pastagem. Minson (1990) relatou que o CMS médio por bovinos em pastagens tropicais está em torno de $50 \mathrm{~g} \mathrm{MS} /(\mathrm{kg} \mathrm{PV})^{0,75}$.

Médias de CMS de pasto, estimadas a partir do CMS de animais suplementados, usando-se a expressão: CMS pasto de animais não suplementados $=$ coeficiente de substituição $(\mathrm{CS})$ * CMS de suplementos + CMS de pasto dos animais suplementados, usando os valores de CS verificados no final de agosto/início de setembro, que resultaram nas médias de CMS de pasto de 1,24 e $1,10 \%$ do PV em 22 a $26 / 09$ e 13 a 17/10, respectivamente, indicaram tendência de redução do consumo de pasto nesse período. Os teores de PB e NDT, este estimado por meio da expressão: concentração de NDT no pasto consumido $=[($ consumo NDT total - consumo NDT suplemento $) /$ CMS pasto] * (concentração NDT no pasto consumido por animais não suplementados/concentração NDT no pasto consumido por animais suplementados), de 20,5 e $24,2 \%$, respectivamente, em 22 a 26/09 e 13 a $17 / 10$, indicaram leve tendência de melhora da qualidade do pasto consumido do final de setembro para outubro. No exame das informações de NDT, torna-se necessário considerar que, quando o CMS é baixo e o animal não atinge o consumo máximo, como provavelmente ocorreu em 27 a 31/10, a concentração de NDT aparente pode não traduzir o valor energético do alimento, porque as perdas endógenas fecais em bovinos são relativamente altas.

Na Tabela 4, são apresentadas as taxas médias de PP, ODF e GPD nos meses de ocupação da pastagem. A lotação animal utilizada nesse trabalho foi semelhante à utilizada por Euclides et al. (1998), de 0,73 a $0,87 \mathrm{UA} / \mathrm{ha}$. Como conseqüência do baixo CMS, os animais ganharam apenas $11,6 \mathrm{~kg}$ de PV em 112 dias, média de $104 \mathrm{~g} /$ dia; no mês de setembro, (período de 2 a 29/9), perderam peso. Esses resulta- 
dos estão coerentes com as conclusões de Leite \& Euclides (1994) e Noller et al. (1997), os quais afirmaram que, durante a seca, o animal pode apresentar baixo CMS e baixo desempenho, mesmo quando há grande disponibilidade de forragem madura na pastagem.

Verificou-se que os ganhos de peso dos animais foram baixos, apesar da alta oferta de MSV, e não houve correlação $(\mathrm{P}>0,05)$ entre GPD e PP ou ODF. O GPD foi, provavelmente, mais influenciado pela acessibilidade do animal ao componente FV e pela qualidade da MSV do que propriamente pela PP ou ODF. No período de 08/07 a 04/08, quando as folhas verdes eram mais acessíveis, os animais apresentaram maior valor de ganho do que em $5 / 8$ a $1 / 9$, quando os estoques de MSV e MSFV eram maiores, porém o componente FV estava menos acessível. No período de 30/09 a 27/10, quando o pasto começou a rebrotar, os animais apresentaram maior $(\mathrm{P}<0,05)$ ganho do que no período de 02 a 29/09, quando o valor da DMSV era maior, porém a qualidade do pasto consumido, provavelmente, era inferior. Coerentemente, constatou-se que os maiores valores para GPD foram verificados nos períodos que ocorreram aumentos na DMSFV (08/7 a 04/8 e 30/9 a 27/10), o que envolve aspectos estruturais, quantitativos e qualitativos da pastagem. Assim, o prolongamento do período de pastejo em condições desfavoráveis à rebrota das plantas forrageiras, provavelmente, contribuiu para o baixo desempenho dos animais, a despeito da forragem acumulada durante o diferimento.
Os resultados parecem indicar também que, em determinadas situações, como essa, em que as taxas de ingestão de MS são baixas e as taxas de oferta de forragem são muito altas, a redução da PP aumentaria apenas, teoricamente, a disponibilidade de forragem por UA ou por quilograma de $\mathrm{PV} / \mathrm{dia}$, já que o animal pode não conseguir utilizá-la e, portanto, não alteraria necessariamente o CMS e o desempenho dos animais. A independência da resposta animal em relação à $\mathrm{PP}$ ou ODF, nessas circunstâncias, pode ser explicada também pelo fato desses fatores não considerarem, para seus cálculos, características dos animais, com a exceção do peso, e características importantes do relvado, com exceção da DMSV, que influenciam o comportamento ingestivo do animal, que nesse caso também é ignorado.

Por outro lado, a constatação de que pastagens de Brachiaria decumbens podem suportar altas lotações, mesmo durante a seca, embora a produção animal verificada seja normalmente muito baixa (Leite \& Euclides, 1994), pode estar relacionada com o baixo consumo de forragem verificado nessas condições, especialmente, quando há alta proporção de forragem madura e/ou morta.

O baixo desempenho de animais, em condições semelhantes a essa, tem sido creditado, freqüentemente, ao baixo CMS, devido à repleção ruminal com forragem de baixa qualidade, fato que pode ser constatado com animais estabulados recebendo forragem de baixa à media digestibilidade. Em pastagens, os animais podem selecionar pasto de

Tabela 4 - Disponibilidade média de matéria seca verde (DMSV), pressão de pastejo (PP), oferta diária de forragem (ODF) e ganho de peso diário (GPD), por período experimental

Table 4 - Mean of availability ( $\mathrm{kg} / \mathrm{ha}$ ) of green herbage dry matter (GHDM) in the beginning of each period, grazing pressure (GP), daily forage allowances (DFA) and average daily live weight gain (ADG), for experimental period

\begin{tabular}{|c|c|c|c|c|}
\hline $\begin{array}{l}\text { Período } \\
\text { Period }\end{array}$ & $\begin{array}{l}\mathrm{DMSV} \\
(\mathrm{kg} / \mathrm{ha}) \\
G H D M \\
(\mathrm{~kg} / \mathrm{ha}) \\
\end{array}$ & $\begin{array}{c}\mathrm{PP} \\
\mathrm{kg} \mathrm{PV}^{1} /(\mathrm{kg} \mathrm{MSV} / \mathrm{dia}) \\
G P \\
\left(\mathrm{~kg} \mathrm{BL}^{1} / \mathrm{kg} \mathrm{GHDM} / \mathrm{d}\right)\end{array}$ & $\begin{array}{c}\text { ODF } \\
(\mathrm{kg} \mathrm{MSV} / \mathrm{dia}) / 100 \mathrm{~kg} \text { PV ou } \% \\
D F A \\
(\mathrm{~kg} G H D M / d / 100 \mathrm{~kg} L W \text { or } \%)\end{array}$ & $\begin{array}{c}\mathrm{GPV} \\
(\mathrm{kg} / \mathrm{dia}) \\
A D G \\
(\mathrm{~kg} / \mathrm{d})\end{array}$ \\
\hline $\begin{array}{l}8 / 7 \text { a } 4 / 8 \\
7 / 8 \text { to } 8 / 4\end{array}$ & $3834^{\mathrm{ab}}$ & 2,45 & 40,7 & $0,347^{\mathrm{a}}$ \\
\hline $\begin{array}{l}5 / 8 \text { a } 1 / 9 \\
8 / 5 \text { to } 9 / 1\end{array}$ & $4021^{\mathrm{a}}$ & 2,34 & 42,7 & $0,067^{\mathrm{a}}$ \\
\hline $\begin{array}{l}2 / 9 \text { a } 29 / 9 \\
9 / 2 \text { to } 9 / 29\end{array}$ & $3250^{\mathrm{ab}}$ & 2,90 & 34,5 & $-0,292^{b}$ \\
\hline $\begin{array}{l}30 / 9 \text { a } 27 / 10 \\
9 / 30 \text { to } 10 / 27\end{array}$ & $2540^{\mathrm{b}}$ & 3,71 & 27,0 & $0,292^{\mathrm{a}}$ \\
\hline
\end{tabular}

Médias seguidas por letras diferentes na mesma coluna diferem $(P<0,05)$ pelo teste Tukey.

Means in the column with different letters differ $(P<.05)$ by Tukey test.

${ }^{1} \mathrm{PV}-\mathrm{Peso}$ vivo (BL - Body live weight). 
melhor qualidade, desde que a disponibilidade de FV e MSV, ou que outros fatores, não restrinjam o CMS e, conseqüentemente, também, o desempenho dos animais. Nesse trabalho, foram observadas disponibilidades de MSV consideradas adequadas, e baixas PP associadas a baixos CMS e desempenho animal, tornando-se necessário o estudo das características da pastagem que, combinadas ou não, pudessem ter condicionado a produção animal. Isso foi realizado concentrando os trabalhos no sentido de identificar fatores da pastagem condicionantes do ganho de peso por meio de correlações. As informações de outubro, mês que caracterizou o início das chuvas, foram excluídas, devido às grandes variações que ocorreram nas características da pastagem.

As equações de regressão ajustadas para GPD em função de características do relvado são apresentadas na Tabela 5. O GPD correlacionou-se $(\mathrm{P}<0,05)$ linear e negativamente com a DMSM, indicando que o material morto presente na pastagem limitou o CMS e o desempenho dos animais. Esse resultado concorda com Euclides et al. (1990), ao afirmarem que o diferimento de uma forrageira leva ao acúmulo de colmo maduro e material morto e decréscimo na disponibilidade de folhas, com conseqüente diminuição do consumo e desempenho animal. Por essas razões, conclui-se também que nem sempre é verdadeira a premissa de que o aumento da disponibilidade de forragem, por meio do diferimento, aumenta a oportunidade de seleção de pasto. Isso se deve ao fato de o diferimento de gramíneas tropicais também conduzir a grande acúmulo de material morto no

Tabela 5 - Equações de regressão para ganho de peso diário ( $Y=$ GPD) em função das disponibilidades de matéria seca morta (DMSM) e das relações entre as disponibilidades de matéria seca verde/matéria seca total (DMSV/DMST) e matéria seca de folha verde/matéria seca morta mais matéria seca de caule verde [DMSFV/ (DMSM + DMSCV)], obtidas em pastagem de Brachiaria decumbens

Table 5 - Estimated regression equations for average daily gain $(Y=A D G)$, in function of availability of dead forage (ADFDM), and availability of green forage/total availability forage ratio (AGFDM/ATFDM), and green leaf/dead forage plus green stem ratio [AGLDM/(ADFDM + AGSDM)], obtained of the Brachiaria decumbens pasture

\begin{tabular}{lcc}
\hline $\begin{array}{l}\text { Regressão } \\
\text { Regressions }\end{array}$ & $\mathrm{r}^{2}$ & $\mathrm{~F}^{1}$ \\
\hline $\mathrm{Y}=2,0082-0,000420 * \mathrm{DMSM}(\mathrm{kg})$ & 1,00 & $*$ \\
$Y=2.0082-.000420 * A D F D M(\mathrm{~kg})$ & & $*$ \\
$\mathrm{Y}=-1,1597+1,473072 * \mathrm{DMSV} / \mathrm{DMSM}$ & 1,00 & \\
$Y=-1.1597+1.473072 * A G F D M / A D F D M$ & & $*$ \\
$\mathrm{Y}=-0,8197+5,499691 * \mathrm{DMSFV} /(\mathrm{DMSM}+\mathrm{DMSCV})$ & 0,95 & \\
$Y=-.8197+5.499691 * A G L D M /(A D F D M+A G S D M)$ & & \\
\hline
\end{tabular}

${ }^{1}$ Significativo a $5 \%$ de probabilidade (Significant at $5 \%$ of probability).

relvado e esse material morto pode condicionar o CMS e o ganho de peso, como ocorreu nesse trabalho.

O GPD correlacionou-se $(\mathrm{P}<0,05)$ linear e positivamente com as relações DMSV/DMSM e DMSFV/ (DMSM + DMSCV). Essas correlações demonstram a importância de forragem verde, especialmente, de folhas verdes na pastagem. A relação DMSFV/ $(\mathrm{DMSM}+\mathrm{DMSCV})$ representa a razão entre a disponibilidade do componente do pasto preferido pelos animais (FV) e as disponibilidades dos componentes menos preferidos (FS e CV) e indesejáveis (CS), concordando com a afirmação de Gomide (1997) de que o animal seleciona folhas verdes e recusa caule e material morto. Não foram verificadas corre- lações $(\mathrm{P}>0,05)$ entre GPD e DMSV e entre GPD e DMSFV, provavelmente, porque as disponibilidades dessas frações não foram fatores limitantes do ganho durante todo o período estudado. Variação na produção e qualidade da forragem e alterações na proporção e distribuição dos componentes FV e MSV nos vários extratos do relvado podem ter contribuído para que não fossem verificadas tais correlações. As demais variáveis estudadas: DMST, DMSV/DMST, DMSFV/DMST e disponibilidade de caule, não se correlacionaram $(\mathrm{P}>0,05)$ com o GPD nas condições desse estudo. A inexistência de correlação entre GPD e DMSV não surpreendeu, uma vez que o GPD já não tinha se correlacionado com PP ou com ODF. 


\section{Conclusões}

O diferimento de sete meses da pastagem de Brachiaria decumbens proporcionou altas disponibilidades de forragem total, forragem verde e morta, antes do período de pastejo.

A utilização contínua da pastagem diferida durante o período seco não afetou a disponibilidade média de forragem total e de forragem morta.

$\mathrm{O}$ mês de setembro caracterizou-se como a época mais crítica da seca, quando as pastagens apresentaram menor disponibilidade e proporção de forragem verde e de folhas verdes, e os animais nas pastagens perderam peso.

O diferimento da pastagem, para utilização na seca, permitiu a manutenção apenas de pequeno ganho de peso dos animais, durante esse período.

O ganho de peso dos animais foi influenciado linear e negativamente pela disponibilidade de forragem morta e linear e positivamente pelas relações disponibilidade de forragem verde/forragem morta e de folha verde/forragem morta mais caule verde, mas não foi influenciado pela simples disponibilidade de forragem verde e folhas verdes.

\section{Literatura Citada}

ALLDEN, W.G.; WHITTAKER, I.A. McD. The determinants of herbage intake by grazing sheep: the interrelationship of factors influencing herbage intake and availability. Australian Journal of Agricultural Research, v.21, n.5, p.755-766, 1970.

BLASER, R.E. Manejo do complexo pastagem-animal para avaliação de plantas e desenvolvimento de sistemas de produção de forragens. In: PEIXOTO, A.M. (Ed.). Pastagens: fundamentos da exploração racional. 2.ed. Piracicaba: Fundação de Estudos Agrários Luiz de Queiroz, 1994. p.279-335.

CORSI, M.; BALSALOBRE, M.A.; SANTOS, P.M.; SILVA, S.C. Bases para o estabelecimento do manejo de pastagens de braquiária. In: SIMPÓSIO SOBRE MANEJO DA PASTAGEM, 1994, Piracicaba. Anais... Piracicaba: Fundação de Estudos Agrários Luiz de Queiroz, 1994. p.249-266.

COSGROVE, G.P. Grazing behaviour and forage intake. In: SIMPÓSIO INTERNACIONAL SOBRE PRODUÇÃO ANIMAL EM PASTEJO, 1997, Viçosa, MG. Anais... Viçosa: UFV, 1997. p.59-80.

EUCLIDES, V.P.B.; EUCLIDES FILHO, K.; ARRUDA, Z.J.; FIGUEIREDO, G.R. Desempenho de novilhos em pastagens de Brachiaria decumbens submetidos a diferentes regimes alimentares. Revista Brasileira de Zootecnia, v.27, n.2, p.246-254, 1998.

EUCLIDES, V.P.B.; ZIMMER, A.H.; OLIVEIRA, M.P. Evaluation of Brachiaria decumbens and Brachiaria brizantha under grazing. In: INTERNATIONAL GRASSLAND CONGRESS, 17., 1993, Rockhampton. Proceedings... Palmerston North: New Zealand Grassland Association, 1993. v.3, p.1997-1998.

EUCLIDES, V.P.B.; VALLE, C.B.; SILVA, J.M. et al. Avaliação de forrageiras tropicais manejadas para produção de feno-em-pé. Pesquisa Agropecuária Brasileira, v.25, n.3, p.393-407, 1990. FARIA, V.P.; PEDREIRA, C.G.S.; SANTOS, F.A.P. Produção de
Bovinos a Pasto. In: SIMPÓSIO SOBRE MANEJO DA PASTAGEM, 13., 1997, Piracicaba. Anais... Piracicaba: Fundação de Estudos Agrários Luiz de Queiroz, 1997. p.1-14.

GOMES JR., P. Composição químico-bromatológica da Brachiaria decumbens e desenvolvimento de novilhos em recria suplementados durante a seca. Viçosa, MG: Universidade Federal de Viçosa, 2000.51p. Dissertação (Mestrado em Zootecnia) - Universidade Federal de Viçosa, 2000.

GOMIDE, J.A. Morfogênese e análise de crescimento de gramíneas tropicais. In: SIMPÓSIO INTERNACIONAL SOBRE PRODUÇÃO ANIMAL EM PASTEJO, 1997, Viçosa, MG. Anais... Viçosa: Universidade Federal de Viçosa, 1997. p.411-429.

GUERRERO, J.N.; CONRAD, B.E.; HOLT, E.C.; WU, H. Prediction of animal performance on bermudagrass pasture from available forage. Agronomy Journal, v.76, p.577-580, 1984.

HODGSON J.; CLARK, D.A.; MITCHELL, R.J. Foraging behavior in grazing animals and its impact on plant communities. In: FAHEY JR., G.C. (Ed.). Forage quality, evaluation, and utilization. Madison: 1994. p.796-827.

HOFMANN, R.R. Anatomía del conducto gastrointestinal. In: CHURCH D.C. (Ed.) El rumiante. Fisiología digestiva y nutrición. Zaragoza: Acribia, 1993. p.15-46.

IVINS, J.D.; DILNOT, J.; DAVISON, J. The interpretation of data of grassland evaluation in relation to the varying outputs of grassland and livestock. Journal British Grassland Society, v.13, p.12-28, 1958.

LEITE, G.G.; EUCLIDES V.P. Utilização de pastagens de Brachiaria spp. In: SIMPÓSIO SOBRE MANEJO DA PASTAGEM, 1994, Piracicaba. Anais... Piracicaba: Fundação de Estudos Agrários Luiz de Queiroz, 1994. p.267-297.

MANNETJE, L; EBERSOHN, J.P. Relations between sward characteristics and animal production. Tropical Grasslands, v.14, n.3, p.273-280, 1980.

McMENIMAN, NP. Methods of estimating intake of grazing animals. In: SIMPÓSIO SOBRE TÓPICOS ESPECIAIS EM ZOOTECNIA, 1997, Juiz de Fora. Anais... Juiz de Fora: SBZ, 1997. p.133-168.

MERTENS, D.R. Predicting intake and digestibility using mathematical models of ruminal function. Journal of Animal Science, v.64, p.1548-1558, 1987.

MINSON, D.J. Forage in ruminant nutrition. San Diego: Academic Press, 1990. 483p.

NOLLER, C.H.; NASCIMENTO JR., D.; QUEIROZ, D.S. Exigências nutricionais de animais em pastejo. In: SIMPÓSIO SOBRE MANEJO DA PASTAGEM, 13., 1997, Piracicaba. Anais... Piracicaba: Fundação de Estudos Agrários Luiz de Queiroz, 1997. p.319-352.

PAULINO, M.F. Estratégias de suplementação para bovinos em pastejo. In: SIMPÓSIO DE PRODUÇÃO DE GADO DE CORTE, 1., 1999, Viçosa, MG. Anais... Viçosa: Universidade Federal de Viçosa, 1999. p.137-156.

SANTOS, E.D.G. Terminação de bovinos em pastagem de Brachiaria decumbens Stapf, durante a estação seca, alimentados com diferentes concentrados. Viçosa, MG: Universidade Federal de Viçosa, 2000. 163p. Dissertação (Mestrado em Zootecnia) - Universidade Federal de Viçosa, 2000.

STOBBS, T.H. The effect of plant structure on the intake of tropical pastures. II. Differences in sward structure, nutritive value, and bite size of animals grazing Setaria anceps and Chloris gayana at various stages of growth. Australian Journal of Agricultural Research, v.24, p.821-829, 1973.

WELCH, J.G. Rumination, particle size and passage from the rumen. Journal of Animal Science, v.54, n.4, p.885-894, 1982.

Recebido em: 22/04/02 Aceito em: 19/05/03

R. Bras. Zootec., v.33, n.1, p.214-224, 2004 